\title{
THE CORRESPONDENCES BETWEEN FORMWORK GEOMETRY AND CONCRETE COMPOSITION IN THE CASE OF FAIR-FACED CONCRETE ELEMENTS
}

\author{
${ }^{1}$ Kitti KÁROLYFI, ${ }^{2}$ Ferenc PAPP \\ ${ }^{1,2}$ Department of Structural and Geotechnical Engineering, Széchenyi István University \\ Egyetem tér 1, H-9026 Győr, Hungary, e-mail: ${ }^{1}$ karolyfi.kitti@sze.hu, ${ }^{2}$ papp.ferenc@sze.hu
}

Received 20 November 2017; accepted 12 April 2018

\begin{abstract}
Modern architecture is unimaginable without fair-faced concrete. However, there is no generally accepted method for design the suitable concrete composition to get the required surface quality. This paper presents the effect of saturation degree on fair-faced concrete surfaces and raises additional research areas with regard to the formwork geometry and packing density of aggregate. This study is the first part of a wider research that aims to work out a method for determination of the adequate saturation degree of cement paste depending on the geometrical proportions of the formwork to reach the highest surface quality.
\end{abstract}

Keywords: Fair-faced concrete, Concrete composition, Packing density, Geometrical proportions

\section{Introduction}

In the case of fair-face concrete elements there are many factors influencing the surface quality; the material of the applied form liners; the applied release agent; the concrete composition; the weather and the construction work [1]. The concrete composition is fundamental to the surface quality and is determined by the properties of the cement, aggregate, additives and admixtures. In the case of fair-faced concrete, generally an oversaturated mixture is recommended to get a high surface quality [2], but there is no exact value for the saturation degree of cement paste. Additionally, the placeability and thereby the optimal saturation degree of cement paste is hardly influenced by the geometry of the formwork. However, to determine the cement paste demand, first the packing density of the grain mixture should be known. Packing 
density, an indicator of how efficiently aggregate particles fill a given volume, influences the fresh and hardened properties of concrete [3]. Since Abrams [4] and Feret [5] there is a general approach that the densest grain mixture is the best for concrete composition. The particle size distribution that gives the highest packing density also gives the most flow-able suspension when the particle volume fraction is prescribed [6]. Additionally, the building industry is responsible for $1 / 3$ of total $\mathrm{CO}_{2}$ emissions [7], especially from cement production; therefore, the sustainability is one of the main focuses of attention in concrete industry. By designing a dense aggregate composition, the strength of hardened concrete will be higher, so less material is required, and the environmental impact could be minimized [8]. There are some existing models for build a dense polydisperse mix, but there is no generally accepted method and only mixtures placed in a formwork having large dimensions (as compared with the maximum size of the particles) were considered in these models [9]. It is still an unanswered question, how the geometrical proportion influences the packing density of a given grain mixture. Additionally, studies have revealed that, the rheological properties of fresh concrete are function of packing density of aggregate [6]. Therefore, if the packing density of the grain mixture in different formworks is known, the rheological properties of fresh concrete can be predicted with the above-mentioned models.

In this paper the authors demonstrate how the saturation degree of cement paste affects the surface quality of a fair-faced concrete wall element. Thereafter, the correspondences between the cement paste demand and packing density of aggregate mixture are revealed. Moreover, the authors give an overview on the existing models for predicting the packing density of granular mixes and make hypothesizes relating to the mix composition and geometrical proportions of the formwork in the case of fair-faced concrete elements.

\section{Experimental program}

In the case of fair-face concrete structures, the application of an oversaturated mixture with a value of $20-40\left[1 / \mathrm{m}^{3}\right]$ is recommended based on the technical literature [2]. However, this is not an exact value and not suitable for every structural element independently of other aspects, for example the formwork geometry and form liner. The goal of this examination is to revise this recommendation. In the experimental program, four samples were constructed with different saturation degree of cement paste and with a fixed geometry. Under the experiment the same water to cement ratio, the same type of cement and aggregate and the same consistency class was used in accordance with Table I.

\section{Table I}

Fixed parameters of the experiment

\begin{tabular}{|c|c|}
\hline Parameter & Applied value or type \\
\hline Water to cement ratio & 0.5 \\
Aggregate type & see Table II-III. and Fig. 1. \\
Cement type & CEM I. 52.5 N white cement \\
Consistency class (flow table test) [10] & F4 \\
\hline
\end{tabular}


The aggregate used was sand and gravel from Danube River with the main characteristics demonstrated in Table II. The technical literature recommends the use of rounded aggregate with high fine content and continuous particle size distribution [11]. Therefore, a fixed proportion of the aggregate fractions were used with fine content of $48.0 \%$ - in accordance with Table III. The particle size distribution of the applied aggregate can be seen in Fig. 1 .

Table II

Main characteristics of the applied aggregate

\begin{tabular}{|c|c|}
\hline Maximum size of the aggregate & $D_{\max }=16 \mathrm{~mm}$ \\
Fineness modulus & $m=5.86$ \\
Uniformity coefficient & $U=37.94$ \\
Effective volume & $7591 / \mathrm{m}^{3}$ \\
Cement paste demand & $2411 / \mathrm{m}^{3}$ \\
Fine content $(d<0.25 \mathrm{~mm})$ & $11.4 \%$ \\
Sand : gravel proportion & $47: 53$ \\
\hline
\end{tabular}

Table III

Applied proportion of aggregate fractions

\begin{tabular}{|c|c|}
\hline Aggregate fractions & Applied proportion [\%] \\
\hline Sorted sand 0/4 & 48.0 \\
Sorted gravel 4/8 & 20.0 \\
Sorted gravel 8/16 & 32.0 \\
\hline
\end{tabular}

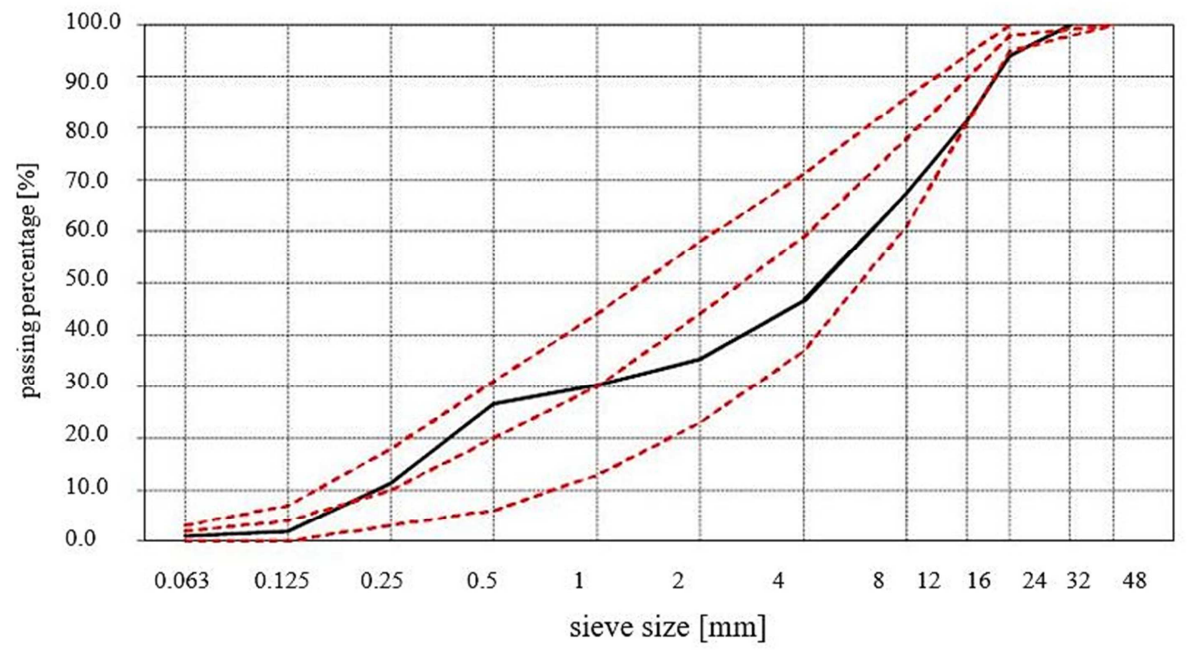

Fig. 1. Particle size distribution of the applied aggregate 
The minimal cement content was determined on the basis of the recommendation of Schlumpf et al. [12]. Table $I V$ shows the mix proportions of the four samples.

The saturation degree of concrete compositions was calculated based on the cement paste demand of the aggregate (see Table II.). The first mixture was a nearly saturated composition with a saturation degree of $+22\left[1 / \mathrm{m}^{3}\right]$. Thereafter the cement and water content were increased in three steps in the same extent, while the water to cement ratio was kept constant. Therefore, the fourth mixture was already a highly oversaturated mixture with a saturation value of $+121\left[1 / \mathrm{m}^{3}\right]$.

Table IV

Variable parameters of concrete compositions [12]

\begin{tabular}{|c|c|c|c|c|c|}
\hline Concrete & \multicolumn{4}{|c|}{ Material $\left[\mathrm{kg} / \mathrm{m}^{3}\right]$} & $\begin{array}{c}\text { Saturation degree of } \\
\text { compont paste }\left[1 / \mathrm{m}^{3}\right]\end{array}$ \\
\cline { 2 - 6 } & Cement & Water & Aggregate & Plasticizer & +22 \\
\hline 1. & 320 & 160 & 1919 & 2.8 & +55 \\
2. & 360 & 180 & 1832 & 1.5 & +88 \\
3. & 400 & 200 & 1745 & 1.0 & +121 \\
4. & 440 & 220 & 1658 & - & \multicolumn{2}{c}{} \\
\hline
\end{tabular}

The formwork used was a thin, wall-like geometry that can be seen in Fig. 2. The performance of the formwork gives the possibility to examine some critical points of fair-faced concrete technology, for example the sharp-angled corner and a small exclusion on a vertical surface.

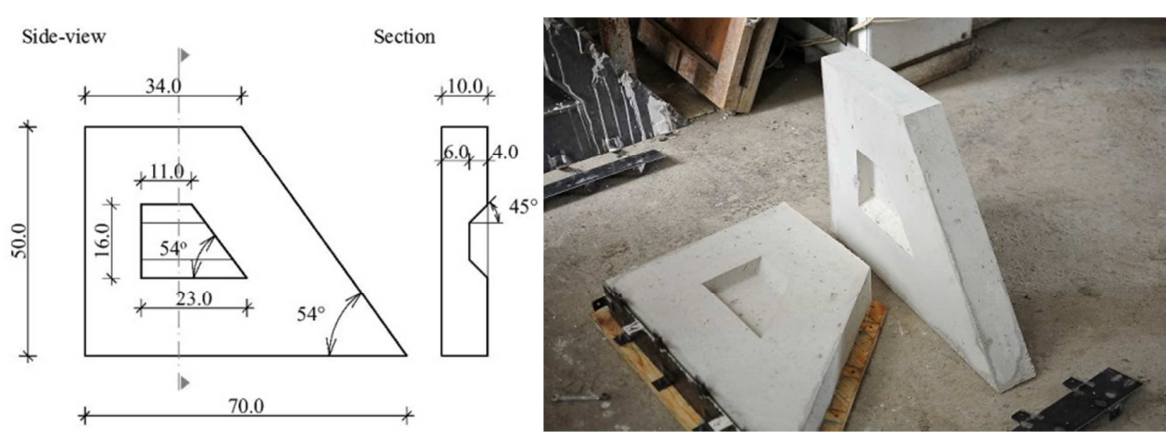

Fig. 2. The geometry of the applied formwork [13]

\section{Results}

The surface quality of the four specimens was examined on the basis of MSZ 248036-3:2010 Hungarian standard [14] and the German Code of Practice for Fair-Faced Concrete [15]. The main aspects of the evaluation were the surface void ratio, discoloration and texture. The surface void ratio of the samples is demonstrated in Fig. 3, and Table $V$ shows the classification of the four samples. 


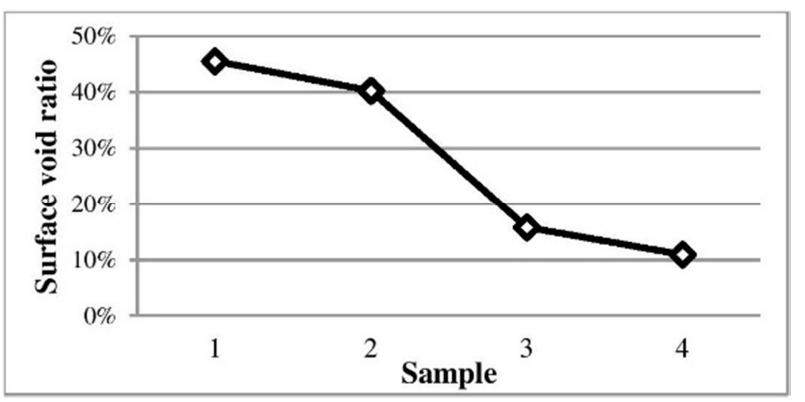

Fig. 3. Average surface void ratio of the samples

Table $V$

Classification of the samples on the basis of the German guideline [13], [15]

\begin{tabular}{|c|c|c|}
\hline Sample & $\begin{array}{c}\text { Saturation degree of } \\
\text { cement paste }\left[1 / \mathrm{m}^{3}\right]\end{array}$ & Classification [15] \\
\hline 1. & +22 & - \\
2. & +55 & SB2 \\
3. & +88 & SB3 \\
4. & +121 & SB4 \\
\hline
\end{tabular}

In this experiment the highest surface quality was provided by the third and fourth sample by the evaluated aspects. As expected, the overall surface quality of the mixtures became even higher with increasing saturation degree in the tested range. This leads to the conclusion that the optimal saturation degree is between 88 and $121\left[1 / \mathrm{m}^{3}\right]$, which value is considerably higher, than the recommended [13].

In the experimental program only one geometry was examined. However, different geometries require different filling ability of fresh concrete to ensure closed, nonporous surface. This is especially important in deep structural members and wall elements, where the exclusions can block the flow, often there is segregation and bleeding, which can result local defects that can reduce the surface quality and mechanical properties of hardened concrete. Therefore, more reliable and comparable experimental data is needed to determine the optimal saturation degree in the case of different geometries. Based upon this the following work hypothesis is proposed by the authors:

I. The optimal saturation degree of cement paste belonging to the highest surface quality will be different in the case of different geometrical proportions of the formwork.

However, the cement paste demand is a function of the particle size distribution and geometrical characteristics of the aggregate [16]. The additional research should therefore be undertaken, as a first step, to define the packing density of the grain mixture considering different geometries and types of aggregate mixtures. 


\section{Packing density of granular mixes}

The value of the packing density of the aggregate mixture needs to be known in two respects: to calculate the aggregate volume that can be compacted in $1 \mathrm{~m}^{3}$ and to determine the amount of cement paste needed to fill the voids between the aggregate particles [17]. The analytical models, which are used to determine the packing density/voids ratio of grain mixtures, are tools that can be used to improve the performance of concrete by minimizing the porosity of the dry mix [3]. The packing density is calculated as:

$$
\phi=\frac{V_{S}}{V_{T}}=\frac{V_{S}}{V_{V}+V_{S}}=1-e,
$$

where $V_{S}$ is the volume of the solids; $V_{T}$ is the total volume; $V_{V}$ is the volume of voids and $e$ is the voids ratio.

The existing methods to build a dense polydisperse mix may be categorized as

1) discrete models and

2) continuous models.

The discrete models are generally based on the assumption that particles are monosized, so every aggregate fraction has a characteristic diameter. Additionally, each class of particle is assumed to be packed to its maximum density in the volume available. The strategy of continuous models is generally to proportion the different aggregate fractions to obtain a grading curve close to an 'ideal' grading curve, which is supposed to produce the maximum packing density. In this case, all possible sizes are present in the particle distribution system [6], [17].

\subsection{Continuous models}

The research of grain mixtures capable to build the densest aggregate skeleton has begun by Feret [5] with the examination of loose sand mixtures. Feret showed that the packing density of aggregate mixtures influences the compressive strength of concrete and the maximum strength is attained when the porosity of the granular mixture is minimal. Fuller proposed grading ('ideal') curves for maximum density, which is described by the following equation:

$$
a=100 \times \frac{d}{D} \text { volume percent, }
$$

where $a$ is the volume percent of particles passing through a sieve with a mesh of $d[\mathrm{~mm}]$, and $D$ is the maximum size of the particles [17], [18]. Caquot [19] introduced the concept of reference concrete, which is actually the densest concrete mixture. In order to obtain the grading curve of the reference concrete (considering the cement content too) Caquot proposed the following equation taking into account the wall effect obtained experimentally: 
$a=\frac{K}{\sqrt[5]{D / d}}$ mass fraction,

where $K$ is a constant depending on the type of aggregate. The theoretical work of Caquot has been put into practice by Faury [20]. Based on Faury's research the aggregate mixture with minimal porosity consists of two fractions; $D / 2-D$ coarse and $d_{0}-D / 2$ fine grains, where $d_{0}$ is the minimal particle size of cement content.

After introducing the terminology of the fineness modulus by Abrams, many researchers have examined what is the minimum amount of cement paste (cement paste demand, $\left.V_{p o},\left[1 / \mathrm{m}^{3}\right]\right)$ by applying a given aggregate mixture characterized by its fineness modulus in order to get the highest density of concrete composition [21]. However, there is no exact solution for the practice, the 'ideal' grading curves proposed by the researchers are very different.

\subsection{Discrete models}

The discrete models can be classified as binary, ternary and multimodal mixture models. In the case of concrete technology, the multimodal mixture model should be applied for the aggregate mixture. However, the multimodal mixture models can be led back to binary mixtures. Most of the packing models deal with limited number of aggregate fractions or assume a simplified grading distribution of each individual granular class. Additionally, these models either deal with particles spherical in shape. Based on the experiments of Jones et al. [22] and Moutassem [3] the following models are the most suitable for concrete mixture proportioning; the Compressible Packing Model (CPM) and the Modified Toufar Model (MTM), therefore these models are considered in this study.

\section{The modified Toufar model}

The MTM assumes that diameter ratios greater than $0.22 \mathrm{~mm}$ will be too large to be situated within the interstices between the larger particles. The result is a packing of the matrix that may be considered as a mixture of packed areas mainly consisting of larger particles, and packed areas that mainly consist of smaller particles with larger particles distributed discretely throughout the matrix of smaller particles. It is convenient to use the MTM for determining packing density when a limited number of input values are required [23]. It is also user-friendly comparing to other packing density models, which are usually more complex [24]. The packing density can be calculated by the following equation:

$$
\phi=\left(\frac{y_{1}}{\phi_{1}}+\frac{y_{2}}{\phi_{2}}-y_{2}\left(\frac{1}{\phi_{2}}-1\right) k_{d} k_{s}\right),
$$


where $\phi$ is the packing density of particle $i ; y_{i}$ is the volume fraction of particle $i$; $k_{d}$ is the factor that determines the influence of the diameter ratio and $k_{s}$ is the statistical factor.

\section{The compressible packing model}

The model of de Larrard [9] is on the brink of the continuous and discrete models that covers combinations of any number of individual aggregate fractions, having any type of size distribution. The CPM is a refined version of a previous model, the linear packing density model, that aims to calculate the virtual packing density, defined as the maximum packing density attainable with a given grain mixture (with maximum compaction), each particle keeping its original shape and being placed one by one. From the virtual packing density, a second model was proposed for calculating the actual packing density called the compressible packing model, [9]

$$
K=\sum_{i=1}^{n} \frac{\frac{y_{1}}{\beta_{i}}}{\frac{1}{\phi}-\frac{1}{\gamma_{i}}},
$$

where $\phi$ is the packing density of particle $I ; \gamma_{i}$ is the virtual packing density of component $i$ in the mixture; $K$ is the partial compaction index that depends on the method of compaction; $\beta_{i}$ is the residual packing density of component $i$ in the mixture.

Additionally, a generalization of the model was performed to include the effect of boundary conditions, for example the effect of rigid fibers introduced in the mixture, the loosening effect and the wall effect due to the formwork. For optimization of dry mixtures, a simplified model was proposed, called the Apollonian model, which corresponds to the intuitive way of building a dense polydisperse mix: placing the maximum volume of coarse grains in a formwork, then adding a maximum volume of particles small enough to fit in the voids of the first fraction, and then repeating the operation until no more grain fractions is available. Based on the numerical simulations, optimal distribution appears rather continuous, close to the classical Faury [20] curves, but with an over-dosage of extreme fractions. De Larrard [9] showed that the concept of a universal ideal grading curve is valid only for particles having the same shape along the whole grading span, and for a given compaction method [9].

Since the packing problem has been a frequently recurring problem of several disciplines, some solutions have been developed for example for dense packing of spheres in the more-dimensional unit cube, to maximize the area of the union of triangles packed in the circle [24]. However, in concrete technology no model exists that is able to predict the packing density of a set of particles as a function of the shape of the particles, their size distribution, the formwork geometry and the mixing process [9]. Up to now, only mixtures placed in infinite volumes have been examined. However, in concrete technology the dimensions of the structure are not necessarily large with respect to the maximum size of aggregate. Although the increase of voids in a formwork due to the contact with its surface, called wall effect can be taken into account in this 
model, the effect of geometrical proportions of the formwork on packing density cannot be predicted. There were some packing measurements carried out on mono-disperse grain fractions placed in cylinders of constant height but variable diameter. The pouring and compacting method was the same. As expected, the packing density increased with the diameter of the formwork, mainly for the coarsest fractions [9]. Based upon this the following work hypothesizes are proposed by the authors:

II. With a given grading span and compaction method, but with different geometrical proportions of the formwork, the packing density of a given aggregate mixture will be different;

III. With given aggregate fractions and compaction method, but with different geometrical proportions of the formwork, the optimal grading curve of the densest aggregate mixture will be different.

\section{Additional research objectives}

\subsection{The goal of the research}

The main objective of this research is to improve the surface quality of fair-faced concrete elements with the tools of concrete mixture proportioning. Based on the first and second hypothesis the effect of the geometrical proportions of the formwork on the packing density of aggregate mix will be examined experimentally and by using the packing models. If the packing density of grain mixtures is known the cement paste demand in the saturated state can be calculated by the given formworks. Starting with a saturated fresh concrete mix, the surface quality can be analyzed by increasing the saturation degree. Finally, the relationship between the geometrical proportions of the formwork, the saturation degree and the surface quality can be drawn. The goal of this program is to work out a model based on the experimental result, with which the optimal aggregate mixture and saturation degree can be calculated depending on the formwork geometry to get the required surface quality (Fig. 4).

\subsection{Research program}

The first step of the research is the design of the formworks for the examinations. Two main types of structural elements will be investigated: wall-like geometries and columns. In the first case, different depth/width proportions and a given height will be applied. Additionally, the effect of exclusions and beveled surfaces can be also examined in the case of wall formworks. For the column formworks different diameters will be applied with different diameter/length and with a given height.

Two concepts will be applied regarding the aggregate composition: on the one hand the packing density of given aggregate mixtures - with the same grading curve - will be examined by the different geometries. On the other hand, the optimal grading curve with varied volume fractions - belonging to the maximum packing density - will be investigated by the geometries. The same aggregate type, release agent and form liner will be applied in course of the whole research. 


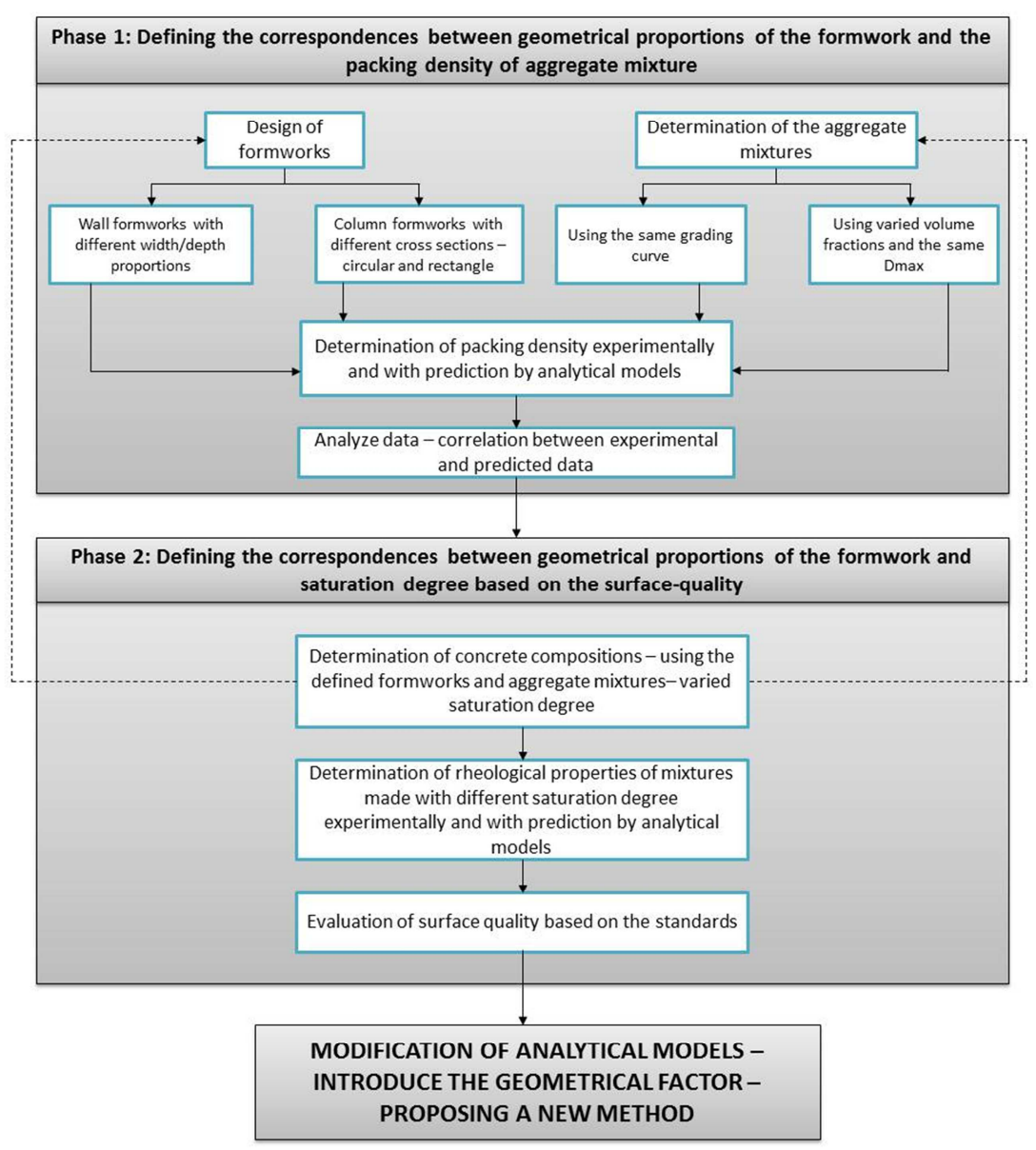

Fig. 4. Research methodology - flow chart

The objective of Phase 2 is the determination of the correspondences between the geometrical proportions of the formwork and saturation degree of cement paste depending on the surface quality. By determination of concrete compositions the formworks and aggregate mixtures defined in the Phase 1 will be applied. In the case of the different geometries the saturation degree will be increased in the same way. The properties of the fresh concrete (plastic viscosity and yield stress) will be measured with a rheometer. The surface quality will be evaluated by the aspects of the Hungarian MSZ 24803-6-3:2012 [14] and German 'Merkblatt Sichtbeton' [15]. Based on the experimental and analytical results the correspondences between the geometrical proportions of the formwork, the concrete composition (saturation degree and 
rheological properties) and surface quality will be revealed in a quantitative way, so the existing methods can be generalized by considering the geometrical factor.

\section{Summary}

The design process of fair-faced concrete surfaces is a complex problem, including many factors influencing the final result. Although there are some guidelines and checklists for supporting the design and construction process, there is not any knowhow to the design of the concrete composition, which is fundamental to the surface quality. Since the same concrete composition cannot be applied to each structure with regard to the geometry, it is necessary to develop the present concrete mixture proportioning methods in order to provide the high surface quality required by the architects. In this paper the authors revealed the problems of determination of the optimal saturation degree of cement paste and proposed a research methodology for working out a design method.

\section{Acknowledgements}

This article was elaborated in the framework of the project EFOP-3.6.1-16-201600017 .

\section{References}

[1] Schultz J. Atlas of exposed concrete, (in German) Vieweg and Teubner, Berlin, 2008.

[2] Kapu L. Fair-faced concrete - architectural concrete, (in Hungarian) TERC Kft, Budapest, 2014.

[3] Moutassem F. Assessment of packing density models and optimizing concrete mixtures, International Journal of Civil, Mechanical and Energy Science (IJCMES), Vol. 2, No. 4, 2016, pp. 29-36.

[4] Abrams D. A. Design of concrete mixtures, Bulletin 1, Structural Materials Research Laboratory, Lewis Institute, Chicago, 1919.

[5] Féret R. Packing densities of mortars, Annales des Ponts et Chaussees, Vol. 4. No 2. 1982, pp. 5-16.

[6] Roussel N. Understanding the rheology of concrete, Woodhead Publishing, 2012.

[7] Porhincák M., Estoková A., Vilceková S. Comparison of environmental impact of building materials of three residential buildings, Pollack Periodica, Vol. 6, No. 3, 2011, pp. 53-62.

[8] Fennis S. A. A. M., Walraven J. C. Using particle packing technology for sustainable concrete mixture design, Delft University of Technology, Delft, 2012.

[9] De Larrard F. Concrete mixture proportioning - A scientific approach (Modern concrete technology), Taylor \& Francis, e-Library, 2011.

[10] EN 12350-5:2009, Testing fresh concrete, Part 5, Flow table test, Hungarian Standards Institution, 2009.

[11] Asztalos I. Fair-faced concrete: What is needed for good end result? (in Hungarian), (Presentation) Chamber of Engineers in Györ-Moson-Sopron County, 2017.

[12] Schlumpf J., Bicher B., Schwoon O. Sika Concrete Handbook, (in German), Sika Services AG, Zürich, 2013. 
[13] Károlyfi K. The effect of saturation degree of cement paste on fair-faced concrete surfaces, Journal of Silicate Based and Composite Materials, Vol. 69, No. 2, 2017, pp. 55-58.

[14] MSZ 24803-1:2012, Specifications for appearance of building structural elements. Part 6-3: Specifications for appearance of concrete and reinforced concrete structures, Requirements for local surface conditions and shape conformity (in Hungarian), 2012.

[15] German code of practice for fair-faced concrete, (in German) German Concrete and Construction Engineering Association (DBV), Federal German Association of the Cement Industry (BDZ), Köln, 2004.

[16] Nehme S. G. Porosity of concrete, PhD Thesis, Budapest University of Technology and Economics, Budapest, 2004.

[17] Mangulkar M. N., Jamkar S. S. Review of particle packing theories used for concrete mix proportioning, International Journal of Scientific \& Engineering Research, Vol. 4, No. 5, 2013, pp. 143-148.

[18] Jones M., Zheng L., Newlands M. D. Comparison of particle packing models for proportioning concrete constituents for minimum voids ratio, Materials and Structures, Vol. 35, No. 5, 2002, pp. 301-309.

[19] Caquot A. Role of Inert Materials in Concrete, (in French) Mémoire de la Société des Ingénieurs Civils de France, 1937.

[20] Faury J. Concrete, (in French), $3^{\text {rd }}$ edition, Dunod, Paris, 1958.

[21] Ujhelyi J. Design of the structure and compressive strength of concrete, (in Hungarian) DSC Thesis, Magyar Tudományos Akadémia, Budapest, 1989.

[22] Jones M., Zheng L., Newlands M. D. Comparison of particle packing models for proportioning concrete constituents for minimum voids ratio, Materials and Structures, Vol. 35, No. 5, 2002, pp. 301-309.

[23] Lensol I. Investigation on reliability of particle packing models for aggregates, Master's Thesis, Luleå University of Technology, 2015.

[24] Vojtech B., Vojtech B. jr., Pavel N. Small selection of old open packing problems, Pollack Periodica, Vol. 7, Suppl. 1, 2012, pp. 21-28. 